\title{
Investigation of the effects of diclofenac sodium in rat ovary on the number of preantral follicles by stereological methods in prenatal period
}

\author{
Neşe Çölçimen ${ }^{1^{\star}}$, Murat Çetin Rağbetlii ${ }^{1}$, Mikail Kara $^{2}$, Okan Arıhan $^{3}$, Veysel Akyol ${ }^{1}$ \\ ${ }^{1}$ Departments of Histology and Embryology, Van Yuzuncu Yil University, Van, Turkey \\ ${ }^{2}$ Departments of Histology and Embryology, Mustafa Kemal University, Hatay, Turkey \\ ${ }^{3}$ Departments of Physiology, V an Yuzuncu Yil University, Van, Turkey
}

\begin{abstract}
For healthy future generations pregnancy is a period in which maximum amount of attention should be given. In this period, choice, duration and dosage of medication as well as the changing physiology of the mother should be taken into account. Non-steroidal anti-inflammatory drugs (NSAIDs) are a group of drugs that have analgesic, anti-pyretic and antiinflammatory effects. This group of drugs can be used in the treatment of the ongoing rheumatic diseases or which occur during the pregnancy period and the complications that occur due to pregnancy. We aimed to show how it affects the number of ovarium preantral follicles of newborn fetus on rats by using Diclofenac Sodium which belongs to this drug family group.

Diclofenac Sodium $\left(1 \mathrm{mg} / \mathrm{kg}\right.$, IM) was injected for 15 days from the $5^{\text {th }}$ day of pregnancy to pregnant rats in Diclofenac Sodium group and saline $(1 \mathrm{ml} / \mathrm{kg}$, IM) was injected to the pregnant rats of the sham group at the same time period. In the $4^{\text {th }}$ week after birth, ovarian tissue preparates of rat pups were stained with hematoxylin-eosin and ovarian total tissue volumes and preantral follicle counts were evaluated under light microscope.

There was no statistically significant difference between groups for ovarium total tissue volumes and preantral follicle numbers $(\mathrm{p}>0.05)$. Lowest value of follicular intensity was observed in Diclofenac sodium group among study groups however no statistically important difference was found $(\mathrm{p}>0.05)$.

Results obtained in our study may be related with administration of drug in not a high dosage $(1 \mathrm{mg} / \mathrm{kg})$. Further studies may be performed with higher doses.
\end{abstract}

Key Words: Diclofenac sodium, ovary, preantral follicle number, rat, stereology

\section{Introduction}

Pregnancy is a very sensitive period for selection and use of drugs since developing fetus may get harm from this administration although those drugs are used for their desired beneficial effects. Drugs and chemical substances may pass placental barrier and pose untoward effects on fetus and they may cause permanent morphological and functional alterations (1). Nonsteroidal Antiinflammatory drugs (NSAID) are used widely since they have analgesic, anti-pyretic, antiinflammatory, anti-thrombotic, anti-cancer and chondroprotective effects (2). In Turkey antibiotics, pain killers and anti-rheumatic drugs are among the mostly used drug groups (3). Among them NSAIDs are also very commonly used in the World. This drug group has a ratio of $25 \%$ among all used drugs in Turkey (4).
Diclofenac, fenoprofen, ibuprofen, indometacine, meklofenamat, flurbiprofen, naproxen, piroxicam and sulindac which are NSAIDs are classified as category $\mathrm{B} / \mathrm{C}$ in first and second trimester and as $\mathrm{D}$ in third trimester by the American Food and Drug Administration (FDA) $(1,5)$. They are used for treatment of rheumatism as well as preterm birth and treatments of complications such as polyhydramnios (6). Since NSAIDs don't cause addiction they are used safely in long term treatment of many rheumatic diseases and generally known as anti-rheumatic drugs (6). They are preferred in musculo-skeletal and joint diseases due to their anti-inflammatory properties (7). In addition Diclofenac Sodium containing drugs are frequently prescribed by Gynecologists and Obstetrics for avoiding preterm birth, symptomatic polyhydramnios and pre-eclampsy and treatment of primary dysmenorrhea,

This work presented as a oral presentation at "International participation XII. National Congress of Histology and Embryology" 27-30 May, 2014, Ankara, Turkey, This work was produced from a doctoral thesis prepared by Nese COLCIMEN 
dysmenorrhea due to intra uterine devices and menorrhagia (6).

In literature, effects of Diclofenac Sodium on over tissue are not elucidated in detail. Although there are studies conducted on effects of Diclofenac Sodium on pregnant and fetus, no study was found on the effect on number of preantral follicle number of ovarium of four weeks old female fetus steorologically. Guven et al. (8) studied over volume and graaf follicle however they did not focus on preantral follicles. In order to contribute for the clarification of the subject we aimed to study effect of Diclofenac Sodium on the fetal reproductive system when used during pregnancy. We focused on overs of fetus and assessed effect of NSAID on morphological volume and preantral follicle number via steorological methods.

\section{Materials and Methods}

Study was initiated with 9 female albino rats obtained from Experimental Medicine Research Center (26.03.2009 No:04). Rats used in the study were weighing 150 to 200 grams and none was copulated prior to the study. An ethical permission was obtained from Animal Studies Ethical Commission. 3 female and 1 male rats which are mixed for copulation were then separated into different cages. Female rats were divided into 3 groups as Diclofenac Sodium (3 individuals), control (3 individuals) and sham (3 individuals). Following copulation, observation of vaginal plaques was accepted as the " 0 day" of pregnancy. Standard pellet and water were given to rats ad libitum under normal light and dark cycle with constant temperature $\left(21 \pm 2{ }^{\circ} \mathrm{C}\right)$. Rats separated for
Diclofenac Sodium group were administered with daily $1 \mathrm{mg} / \mathrm{kg}$ Diclofenac Sodium (Diclofenac Sodium, $75 \mathrm{mg} / 3 \mathrm{ml}$ ampulla) intramuscular (I.M) for 15 days following the $5^{\text {th }}$ day of their pregnancy. Same amount of saline was injected to pregnant rats in sham group. No intervention was administered to control group. Each rat was caged individually prior to labor. Postnatal offspring were separated into different cages as males and females. Diclofenac Sodium, control and sham groups were formed with 6 individuals per group which are all aged 4 weeks. Infant female rats were anesthetized with ketamine $(50 \mathrm{mg} / \mathrm{kg})$ and perfused with $10 \%$ neutral formaldehyde via intracardiac route. In the perfused animals, lower abdominal incision was administered and position of right over was localized within the abdominal cavity. Then over was extracted with uterus. Obtained overs were detached from their tuba uterina and paraffin blocks were prepared after completing routine histological procedures. Slices of $5 \mu \mathrm{m}$ thickness obtained from paraffin blocks were deparaffinized and were exposed to Hematoxylineosin staining. Follicles were classified according to their progress stages in accordance with the relevant literature on the subject. Prenatal follicles were evaluated in our study (Fig. 1). For the volume measurement of steorological analysis a modified method of Cavalieri principle was used (9). Following total tissue volume ratios were measured with dotted area ruler which is provided in Shetereom 1.5 version software program $(10,11)$. AxioVision 3,1 (Zeiss axioplan 2 imaging Germany, Göttingen) program was used for imaging. Ovarium total tissue volumes, densities of preantral follicle numbers were compared with Kruskal-Wallis test.
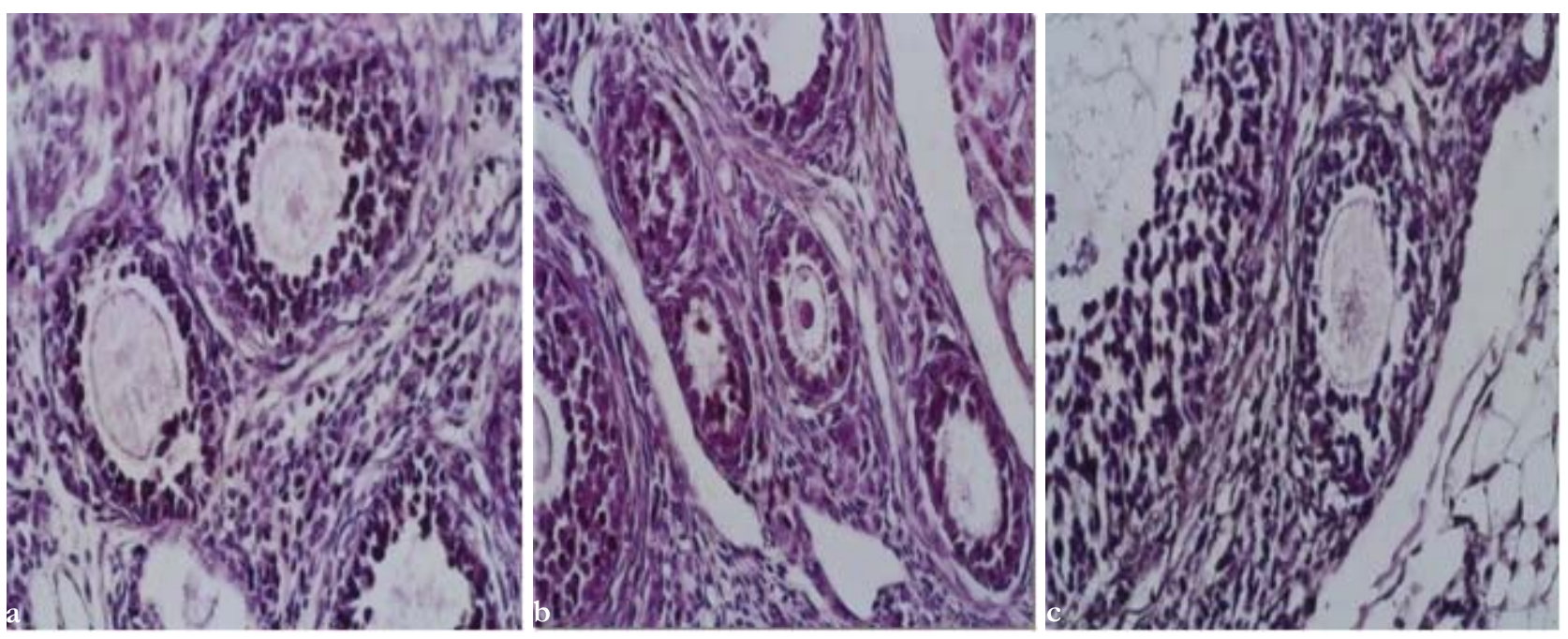

Fig. 1-a: View of follicles in an ovarian section from the control group b: View of follicles in an ovarian section from the Diclofenac Sodium group. c: View of follicles in an ovarian section from the sham group. 
Table 1. Descriptive statistics and comparative results

\begin{tabular}{llccccccc}
\hline Variable & Group & $\mathrm{N}$ & Median & Mean & St. Dev. & Min. & Max. & $\mathrm{p}$ \\
\hline \multirow{3}{*}{ Ovarium Volume } & Diclofenac Sodium & 6 & 0.039 & 0.038 & 0.004 & 0.033 & 0.043 & \\
& Control & 6 & 0.036 & 0.040 & 0.09 & 0.033 & 0.057 & 0.514 \\
& Sham & 6 & 0.036 & 0.036 & 0.02 & 0.032 & 0.039 & \\
\hline \multirow{2}{*}{ Preantral Follicle } & Diclofenac Sodium & 6 & 3080900 & 3833720 & 2255548 & 2359400 & 8331360 & \\
Numerical & Control & 6 & 6145640 & 5969260 & 2278184 & 2730200 & 8404760 & 0.133 \\
Intensity & Sham & 6 & 3216600 & 3555873 & 1811412 & 1141720 & 6619200 & \\
\hline
\end{tabular}

Results are presented as mean / median \pm standard deviation $(\mathrm{P}<0.05)$.

Table 2. Volumetric point numbers of Diclofenac Sodium groups and Total volume of ovary

\begin{tabular}{lcc}
\hline Rat & $\begin{array}{c}\text { Volumetric } \\
\text { point numbers }\end{array}$ & $\begin{array}{c}\text { Total volume } \\
\text { of ovary }\left(\mathrm{cm}^{3}\right)\end{array}$ \\
\hline $\begin{array}{l}\text { Diclofenac } \\
\text { Sodium 1 }\end{array}$ & 1556 & 0.0406 \\
$\begin{array}{l}\text { Diclofenac } \\
\text { Sodium 2 } \\
\text { Diclofenac }\end{array}$ & 2433 & 0.0330 \\
Sodium 3 & 1371 & 0.0396 \\
$\begin{array}{l}\text { Diclofenac } \\
\text { Sodium 4 } \\
\text { Diclofenac }\end{array}$ & 3063 & 0.0341 \\
Sodium 5 & 1255 & 0.0425 \\
Diclofenac \\
Sodium 6
\end{tabular}

\section{Results}

Coefficient of Variation values of groups (CV), were 0.13 in Diclofenac Sodium group, 0.19 in sham group and 0.21 in control group $(\mathrm{p}<0.01)$. Therefore number of rats was considered as sufficient. Coefficient of error (CE) in groups were determined as 0.0379 in Diclofenac Sodium group, 0.0360 in sham group, 0.0344 in control group. Therefore it is accepted as $\mathrm{P}<0.10$.

When total volume of ovarium of Diclofenac Sodium group was compared with control group, no change in ovarium total volume was detected and values were not statistically significant $(\mathrm{P}>0.05)$ (Table 2,3,4). When ovarium total preantral follicle numbers of Diclofenac Sodium group and control group were compared, no statistically significant change was detected $(\mathrm{P}>0.05)$ (Table 5) (Table 1).

\section{Discussion}

NSAIDs show their anti-inflammatory, antipyretic and analgesic properties via inhibiting Cyclooxigenase- 1 and 2 which are key enzymes for prostanoid formation $(12,13)$. Inhibition of such enzymes does not only attenuate prostanoid level but also affect Renin-Angiotensin-Aldosteron system and may have an impact on kidney and many pathophysiological processes by affecting renal vascular tonicity. NSAIDs are among the mostly used drugs in the World and Turkey (4).

Table 3. Volumetric point numbers of Sham groups and Total volume of ovary

\begin{tabular}{lcc}
\hline Rat & $\begin{array}{c}\text { Volumetric point } \\
\text { numbers }\end{array}$ & $\begin{array}{c}\text { Total volume } \\
\text { of ovary }\left(\mathrm{cm}^{3}\right)\end{array}$ \\
\hline Sham 1 & 1241 & 0.0385 \\
Sham 2 & 2340 & 0.0354 \\
Sham 3 & 2298 & 0.0321 \\
Sham 4 & 2758 & 0.0367 \\
Sham 5 & 1719 & 0.0382 \\
Sham 6 & 1655 & 0.0353 \\
\hline Mean & 2001.83 & 0.0360 \\
\hline
\end{tabular}

Table 4. Volumetric point numbers of Control groups and Total volume of ovary

\begin{tabular}{lcc}
\hline Rat & $\begin{array}{c}\text { Volumetric point } \\
\text { numbers }\end{array}$ & $\begin{array}{c}\text { Total volume } \\
\text { of ovary }\left(\mathrm{cm}^{3}\right)\end{array}$ \\
\hline Control 1 & 1216 & 0.0430 \\
Control 2 & 1324 & 0.0382 \\
Control 3 & 935 & 0.0570 \\
Control 4 & 2293 & 0.0342 \\
Control 5 & 2385 & 0.0342 \\
Control 6 & 2309 & 0.0334 \\
\hline Mean & 1743.66 & 0.0344 \\
\hline
\end{tabular}


Çölçimen et al / Number of preantral follicles in rat ovary

Table 5. Number of ovary total primordial follicles of the groups

\begin{tabular}{lcc}
\hline Rat & $\begin{array}{c}\text { Number of ovary total primordial cells } \\
(\mathrm{N})\end{array}$ & $\begin{array}{c}\text { Number of ovary primordial cells } \\
(\mathrm{Q}-)\end{array}$ \\
\hline Diclofenac Sodium 1 & 3688.74 & 211 \\
Diclofenac Sodium 2 & 3547.36 & 258 \\
Diclofenac Sodium 3 & 5081.99 & 295 \\
Diclofenac Sodium 4 & 3956.31 & 264 \\
Diclofenac Sodium 5 & 4634.71 & 249 \\
Diclofenac Sodium 6 & 6012.35 & 285 \\
Control 1 & 2918.14 & 322 \\
Control 2 & 5536.86 & 248 \\
Control 3 & 4308.11 & 273 \\
Control 4 & 4541.65 & 244 \\
Control 5 & 5644.85 & 315 \\
Control 6 & 9174.92 & 274 \\
\hline
\end{tabular}

Those drugs are used increasingly since they don't cause addiction during long term use which is essential for the treatment of the rheumatic diseases (14). Acetylsalicylic acid is the prototype of NSAIDs. In a study conducted in USA in 1991, it was found that 6000 tons of acetylsalicylic acid was used per year (15). In our study we used non selective Diclofenac Sodium which is belonging to NSAID group. In the last 20 years Diclofenac Sodium are sold in different names (Voltaren, miyadren, dikloron, etc.) in Turkey (16). Diclofenac Sodium which has a common use has been shown to deteriorate many organ and tissue structures and cause side effects in many systems. Among the most well-known side effects are as follows; ulceration, bleeding, stomatitis in stomach; acute renal failure, hypertension, interstitial nephritis in kidney; erythema multiforme, bullous eruptions, eruptions, drug eruptions, pustular psoriasis in skin; hepatitis, Reye syndrome in liver; aseptic meningitis, head ache, dizziness, nausea in central nervous system; aplastic anemia, thrombocytopenia, neutropenia, hemolytic anemia in blood; pulmonary edema, pulmonary alveolitis, asthma and anaphylactic reactions in lungs $(7,14)$.

Treatment of active rheumatic diseases during pregnancy is vital for both mother's health and for proper development of fetus. Present knowledge about use of anti-rheumatic drugs during pregnancy is limited since conducting prospective clinical studies during that period are not ethical. Therefore it must be considered well before using NSAIDs in order to avoid preterm birth or treatment of rheumatic disease (6). It was reported that NSAID use during pregnancy cause side effects in both mother and the fetus. It was observed that administration of Diclofenac Sodium during pregnancy prolongs pregnancy period and decreased number of litters. Kökçü et al. (17) compared the pregnancy period and distribution of number of litters in Diclofenac Sodium administered and non-administered groups and reported pronounced differences. In experimental studies normal pregnancy period of rats prolong from 21-23 days to 28-29 days due to NSAIDs. Same situation was also observed in pregnants using NSAIDs $(18,19)$. We observed no alteration in period of pregnancy or birth in our study. Chan et al. (20) administered different doses of Diclofenac Sodium to pregnant rats and found teratogenic effects due to high dosage. Carp et al. (21), administered $3 \mathrm{mg} / \mathrm{kg}$ Diclofenac Sodium to rats and observed almost complete prevention of blastocyte implantation of rat embryos. Contraction in Ductus Arteriosus (DA), hydrops fetalis, oligohydroamnios, ileal perforation, cystic lesions in brain and parenchymal degeneration especially in liver were observed in postnatal period due to NSAID use in pregnancy (6). Needs and Brooks (22), administered $4 \mathrm{mg} / \mathrm{kg}$ Diclofenac Sodium to rat embryos and observed rib defects in fetus. These studies reveal that different effects may occur on fetus due to different doses of Diclofenac Sodium administered in different time periods of pregnancy. On the other hand Russell (23) reported no teratogenic effect of $10 \mathrm{mg} / \mathrm{kg}$ Diclofenac Sodium administration on rabbits. In our study we did not observe a teratogenic effect during investigation of delivered offspring. Üstün et al. (24) investigated overs of Diclofenac Sodium $(0.2 \mathrm{mg} / \mathrm{kg})$ administered rats histopathologically and observed significant decrease in secondary follicle number compared to control and no significant difference in alteration of tertiary follicle number. In our study we did not find a change in preantral follicle number. Güven et al. 
(8) investigated ovarium (medulla, cortex, Graaf follicle and corpus luteum volumes as well as granulosa, teka cells and anthrum volumes) and volumes of uterine horns steorologically on female rats which were exposed to Diclofenac Sodium during their prenatal life period. No significant change in volumes of tissues was detected and this finding is parallel with total volume finding in our study.

Recent observations of rare congenital anomalies in Turkey (such as Jarko-Levin Syndrome, Spondylocostal Dysostosis) also support common use of NSAIDs in Turkey. Therefore it is advised to be cautious during prescription of NSAIDs such as Diclofenac Sodium in pregnancy by the physicians (7).

In our study effect of prenatal administration of Diclofenac Sodium $(1 \mathrm{mg} / \mathrm{kg})$ on postnatal 4 weeks of aged rat ovarium preantral follicle number and on total tissue volume by steorological methods were studied and no statistically difference was observed between groups (Diclofenac Sodium, sham and control). Results obtained in our study may be related with dosage of administered drug $(1 \mathrm{mg} / \mathrm{kg})$ which is not very high compared to higher doses in literature. Further studies may be performed with higher doses and focus on density of follicle granulosa cell mitochondria via steorological methods using electron microscopy.

Acknowledgments: This study was supported by funds from The Scientific Research Council of Van Yuzuncu Yil University (YYU, BAPK, Project no:2013-SBYE-D053).

\section{References}

1. İskit $\mathrm{AB}$. Drug selection in pregnant patients. Continuing Education Journal 2007; 16: 15-17.

2. Satılmış M, Bilgili A. Nonsteroidal antiinflammatory drug new use options. Rewiew Article. Journal of Faculy Veterinary Medicine, Erciyes University 2013; 10: 63-71.

3. Pinar N. Drug expenditures in our country / Review, Journal of Turgut Ozal Medical Center 2012; 19: 59-65.

4. Gökalp O, Mollaoğlu H. Inappropriate drug use. Süleyman Demirel University Faculty of Medicine Journal 2003; 10: 17-20.

5. Lucas S. Medication use in the treatment of migraine during pregnancy and lactation. Curr Pain Headache Rep 2009; 13: 392-398.

6. Gökçimen A, Malas MA. Review of literature on nonsteroidal anti-inflammatory drugs in pregnancy toxicities. Süleyman Demirel University Faculty of Medicine Journal 2003; 10: 50-52.
7. Odacı E, Korkmaz A, Ayas B, Rağbetli MÇ, Çiftçi N. Effect of Prenatal Diclofenac Sodium exposure onthe rat articular Cartılage of the rat in postnatal period. Turkey Clinics Journal of Medical Sciences 2001; 21: 278-281.

8. Güven D, Altunkaynak BZ, Ayranci E, et al. Stereological and histopathological evaluation of ovary and uterine horns of female rats prenatally exposed to diclofenac sodium. Journal of Obstetrics \& Gynaecology 2013; 33: 258-263.

9. Gundersen HJ, Jensen EB. The efficiency of systematic sampling in stereology and its prediction. J Microsc 1987; 147: 229-263.

10. Gundersen HJ, Bendtsen TF, Korbo L, et al. Some new, simple and efficient stereological methods and their use in pathological research and diagnosis. APMIS 1988; 96: 379-394.

11. Howard C.V. Reed M.G. Unbiased stereology, threedimensionel measurements in microscopy (pp. 3968). Oxford: BIOS Scientific Publishers 1998.

12. Hasçelik Z. Nonsteroidal antiinflammatory drugs. Continuing Education Journal 2001; 10: 1.

13. Duman EN. The role of NSAIDs in the treatment of chronic pain. Clinical Development Journal 2007; 20: 145-149

14. Özbudak H, Ünal AZ, Sabuncuoğlu S. Evaluation of the use of non-steroidal antiinflammatory drugs in pregnancy. Marmara Pharmaceutical Journal 2016; 20: 64-71. DOI:10.1291/mpj.20162059818.

15. Weissmann G. Aspirin. Sci Am 1991; 264: 84-90.

16. Ommaty R. Vademecum 2003. Modern drug guide. 23. Edition. 492-1192. Feryal printing press. Ankara, 2003.

17. Kökçü A, Üstün C, Çokşenim Ş, Balat Ö. The effect of Diclofenac Sodium administered to the pregnant rat on fetal number and pregnancy duration. T Klin Jinekol Obst 1992; 2: 295-229.

18. Ostensen M. Treatment of inflammatory rheumatic disorders in pregnancy: what are the safest treatment options? Drug Saf 1998; 19: 389-410.

19. Ostensen M. Nonsteroidal anti-inflammatory drugs during pregnancy. Scand J. Rheumatol Suppl 1998; 107: 128-132.

20. Chan LY, Chiu PY, Siu SS, Lau TK. A study of diclofenac-induced teratogenicity during organogenesis using a whole rat embryo culture model. Hum Reprod 2001; 16: 2390-2393.

21. Carp HJ, Fein A, Nebel L. Effect of diclofenac on implantation and embryonic development in the rat. Eur J Obstet Gynecol Reprod Biol 1988; 28: 273277.

22. Needs CJ, Brooks PM. Antirheumatic medication in pregnancy. Br J Rheumatol 1985; 24: 382-390.

23. Russell JG. Antirheumatic medication in pregnancy. Br J Rheumatol 1986; 25: 229.

24. Üstün C, Kökçü A, Çokşemin Ş, Kandemir B. Effect of prostaglandin synthesis inhibitor Diclofenac Sodium on ovarian folliculogenesis in rats. T Klin Jinekol Obst 1993; 3: 70-72. 